\title{
Beyond Human Leukocyte Antigen Class I Antigens: Hereditary Hemochromatosis Gene Mutations in Recurrent Aphthous Oral Ulcers and Behçet Disease in the South of Tunisia
}

\author{
Sahar ElAoud ${ }^{a}$ Arwa Kamoun $^{b}$ Nadia Mahfoudh ${ }^{b}$ Aida Charfi ${ }^{b}$ Mouna Snoussi ${ }^{a}$ \\ Hend Hachicha ${ }^{c}$ Ameni Jerbi ${ }^{c}$ Chifa Dammak ${ }^{a}$ Feten Frikha ${ }^{a}$ Faiza Hakim ${ }^{b}$ Lilia Gaddour ${ }^{b}$ \\ Zouheir Bahloul $^{\text {a }}$ Hafedh Makni ${ }^{\text {b }}$ \\ Departments of a Internal Medicine and ${ }^{\mathrm{b}}$ Histocompatibility, Hedi Chaker Hospital, and ${ }^{\mathrm{C}}$ Immunology Department, \\ Habib Bourguiba Hospital, Sfax, Tunisia
}

\section{Significance of the Study}

- In this study, HLA-B51 carriage increased the risk of skin involvement in Behçet disease and in recurrent aphthous oral ulcers (RAOU). Hence, HFE could be a potential susceptibility gene for isolated RAOU.

\section{Keywords}

Behçet disease $\cdot$ Recurrent aphthous oral ulcers $\cdot$ Human leukocyte antigen class I polymorphism · Hereditary hemochromatosis gene mutations

\begin{abstract}
Objective: The aim of this work was to establish human leukocyte antigen (HLA) class I and hereditary hemochromatosis gene (HFE) mutation associations with recurrent aphthous oral ulcers (RAOU) and Behçet disease (BD) in a cohort of Southern Tunisian patients. Subjects and Methods: A total of 232 patients with RAOU and 123 healthy controls (HCs) were enrolled in this study. The patients were divided into 2 groups based on the presence (BD+: $n=62$ ) or absence of $B D$ (BD-, $n=170)$. In the BD+ group, 28 patients had severe manifestations of BD. In the BD- group, RAOU was isolated in 81 patients, associated with mucocutaneous manifestations in 58 and with joint symptoms in 25. Complement-dependent microlymphocytotoxicity assay and polymerase
\end{abstract}

\section{KARGER}

E-Mail karger@karger.com www.karger.com/mpp
This is an Open Access article licensed under the Creative Common Attribution-NonCommercial-4.0 International License (CC BY-NC) (http://www.karger.com/Services/OpenAccessLicense), applicable to the online version of the article only. Usage and distribution for commercial purposes requires written permission. chain reaction-restriction fragment length polymorphism were used to study HLA class I polymorphism and HFE mutations, respectively. Results: HLA-B51 was positively associated with $\mathrm{BD}$, particularly in those with severe manifestations. No association was detected with HLA class I polymorphism among the BD group. Based on stratification to clinical manifestations, the isolated RAOU was negatively associated with HLA-A1 with a difference close to significance (12 [14.81\%] vs. 32 [26.02\%] in HCs; $p=0.06)$. Furthermore, patients with mucocutaneous features had a higher frequency of HLA-B51 $(14,24.14 \%)$ than patients without mucocutaneous involvement $(11,11.37 \%)$. Considering HFE mutations, patients with isolated RAOU had a higher frequency of H63D when compared with other subgroups, especially after limiting the comparison to 27 patients of at least 5 years of followup. Conclusion: This study showed that, unlike BD, RAOU were not associated with HLA-B51. Moreover, we suggest that H63D mutation was positively associated with isolated RAOU.

(c) 2017 The Author(s)

Published by S. Karger AG, Basel 


\section{Introduction}

Recurrent aphthous oral ulcers (RAOU) are characterized by recurrent inflammatory painful ulcers that recur at intervals of a few days or months. The condition is reported to affect $20 \%$ of the general population at any time [1]. Three clinical presentations of RAOU have been recognized: minor recurrent aphthous stomatitis, major recurrent aphthous stomatitis, and herpetiform ulceration. These lesions can be isolated alone or in combination with other conditions, or as part of a multiorgan syndrome, especially Behçet disease (BD) [2].

$\mathrm{BD}$ is a multisystem inflammatory disorder. It is characterized by skin, ocular, joint, central nervous system, vascular, and intestinal manifestations of varying severity [2]. ROAU is often the initial feature in most patients with $\mathrm{BD}$ and is a major criterion according to the International Study Group for Behçet's Disease criteria for the diagnosis of this disease [3]. It is generally present with at least 2 of the following: recurrent genital ulceration, eye lesions, skin lesions, or a positive pathergy test [2]. It is difficult to predict those patients initially presenting with ROAU who will subsequently proceed to develop other features of $\mathrm{BD}$.

Histocompatibility human leukocyte antigen (HLA) typing is not a diagnostic criterion for BD. Nevertheless, studies on HLA associations with BD considered HLAB51 antigen as the strongest evidence of a BD genetic background. Indeed, some reports also implicated the probable role of HLA antigen inheritance in the RAOU immunopathogenesis [4-5].

The hereditary hemochromatosis gene (HFE) is a major histocompatibility class I-like molecule. It is located on the short arm of chromosome 6, approximately $4 \mathrm{Mb}$ telomeric to the HLA-A locus [6]. Linkage disequilibrium was demonstrated between the HFE mutations and HLAA and HLA-B alleles in particular [7]. The HFE mutation is encountered in hereditary hemochromatosis [6]. It is also implicated in other diseases, such as neoplasia [8-10] and myelodysplastic syndromes [11]. Its association with RAOU or BD has not yet been described. Therefore, the aim of this study was to investigate whether or not HLA class I and HFE mutations are associated with RAOU and $\mathrm{BD}$ in a group of Southern Tunisian patients.

\section{Materials and Methods}

\section{Study Population}

The study included 232 patients with RAOU who were seen from January 2007 to December 2013 at the Department of Internal Medicine, Hedi Cheker University Hospital, Sfax, Tunisia. The patients included in this study were selected from subjects enrolled in an ongoing case-control study designed to investigate the frequency of the different alleles HLA-A and HLA-B in these patients, and to study different HFE mutations in linkage disequilibrium with these HLA antigens.

The clinical features of the patients are shown in Table 1. The patients with RAOU were divided into 2 groups based on the presence $(\mathrm{BD}+)$ or absence (BD-) of $\mathrm{BD}$. The diagnosis of $\mathrm{BD}$ was made according to the criteria of the International Study Group for Behçet's Disease.

The $\mathrm{BD}+$ group included 62 patients ( 41 men and 21 women). Severe cases were defined as those with at least 1 ocular, gastrointestinal, vascular, or neurological involvement (28 patients).

The BD-group included 170 patients ( 76 men and 94 women). RAOU was isolated in 81 patients and associated with other clinical features in 89 patients in whom the criteria for BD were not fulfilled (Table 1). The associated manifestations were distributed as follows: mucocutaneous manifestations were found in 58 patients and joint symptoms in 25 patients. Mucocutaneous features included genital ulcers, a positive pathergy test, and erythema nodosum. Five patients had uveitis and 1 patient experienced venous thrombosis. These 6 latter patients were excluded from HLA class I and HFE subgroup analysis.

For healthy controls (HCs), 123 unrelated healthy Tunisian subjects with no history of RAOU were recruited. All patients and controls gave written informed consent for their participation in the study.

\section{Laboratory Methods}

The HLA-class I (A and B) typing was performed on freshly peripheral blood mononuclear cells separated on a Ficoll gradient from $20 \mathrm{~mL}$ of citrate-phosphate-dextrose-collected venous blood, by the standard complement-dependent microlymphocytotoxicity assay. For HFE mutations analysis, DNA was extracted from 5 $\mathrm{mL}$ of heparinized blood by the salting out technique. The DNA was available for our $123 \mathrm{HCs}$ and 208 patients. The identification of H63D, C282Y, and S65C mutations was carried out by polymerase chain reaction-restriction fragment length polymorphism [12].

\section{Statistical Analysis}

Data analysis was performed using the Statistical Package for Social Sciences (version 20.0; SPSS, Chicago, IL, USA). A value of $p<0.05$ was regarded as statistically significant. Odds ratios (OR) and $95 \%$ confidence intervals (CI) were calculated according to the Woolf method.

\section{Results}

\section{HLA Class I}

For the BD+ groups, the association of HLA class I antigens with $\mathrm{BD}$ based on clinical manifestations and in comparison with HCs is summarized in Table 2. Regarding the epidemiological findings, women had a higher frequency of HLA-B14 than male patients (4 [19.05\%] vs. $1[2.44 \%] ; p=0.023)$. For the clinical aspects, the frequen- 
Table 1. Patient repartition according to clinical features

\begin{tabular}{lllll}
\hline BD- $(n=170 ; 76$ male and 94 female $)$ & & $\mathrm{BD}+(n=62 ; 41$ male and 21 female $)$ \\
\hline SG1 & Isolated RAOU & 81 & SGA & No severe BD \\
SG2 & RAOU with mucocutaneous manifestations & 58 & SGB & $\begin{array}{l}\text { Severe BD with uveitis, neurological, } \\
\text { or vascular involvement }\end{array}$ \\
SG3 & RAOU with joint involvement, without & 25 & & \\
& mucocutaneous manifestations & & & \\
\hline
\end{tabular}

BD, Behçet disease; RAOU, recurrent aphthous oral ulcers; SG, subgroup.

Table 2. HLA class I association with BD according to clinical manifestations and in comparison with $\mathrm{HCs}$

\begin{tabular}{lllll}
\hline $\begin{array}{l}\text { HLA } \\
\text { antigen }\end{array}$ & $\begin{array}{l}\text { BD+ } \\
(n=62)\end{array}$ & $\begin{array}{l}\text { SGA } \\
(n=34)\end{array}$ & $\begin{array}{l}\text { SGB } \\
n=28)\end{array}$ & $\begin{array}{l}\text { HCs } \\
(n=123)\end{array}$ \\
\hline A1 & $15(24.19)$ & $6(17.6)$ & $9(32)$ & $32(26.02)$ \\
A23 & $6(9.68)$ & $4(11.8)$ & $2(7.1)$ & $10(8.13)$ \\
A24 & $4(6.45)$ & $1(2.9)$ & $3(10.7)$ & $20(16.26)$ \\
B8 & $5(8.06)$ & $3(8.8)$ & $2(7)$ & $16(13)$ \\
B27 & $3(4.84)$ & $2(5.9)$ & $1(3.6)$ & $3(2.44)$ \\
B35 & $4(6.45)^{*}$ & $2(5.9)$ & $2(7.1)$ & $21(17.07)$ \\
B51 & $17(27.42)^{* *}$ & $8(23.5)$ & $9(32)^{* * *}$ & $12(9.76)$ \\
\hline
\end{tabular}

Data are presented as $n(\%)$. BD, Behçet disease; SG, subgroup; HCs, healthy controls. Compared with HCs: ${ }^{*} p=0.046$ (OR 0.33, 95\% CI $0.11-1.01$ ); ${ }^{* *} p=0.002$ (OR 2.03, 95\% CI 1.54-7.89); *** $p=0.005$ (OR $4.38,95 \%$ CI 1.62-11.81).

cy of HLA-B51 positivity was significantly higher in BD+ patients compared to the control group (17 [27.42\%] vs. 12 [9.76\%]; $p=0.002)$. However, the HLA-B35 was less frequent in $\mathrm{BD}+$ patients when compared to the HCs (4 [6.45\%] vs. 21 [17.07\%]; $p=0.046)$. Among 34 patients without severe manifestations, $9(26.47 \%)$ had joint involvement. HLA-B51 was expressed in none of them.

Regarding the $\mathrm{BD}$ - group, the association of HLA class I antigens with RAOU based on clinical manifestations and in comparison with HCs is summarized in Table 3, and no association was detected between HLA class I polymorphism and RAOU. The male patients had a higher frequency of HLA-A68 (9 [11.8\%] vs. 3 [3.1\%]; $p=$ 0.03 ) and of HLA-B45 (9 [11.8\%] vs. $1[1 \%] ; p=0.003$ ) than female patients. Based on stratification to clinical manifestations, HLA-A1 was less frequent in the patients with isolated RAOU than HCs (12 [14.81\%] vs. 32 [26.02\%]; $p=0.06)$. HLA-B51 was positively associated with mucocutaneous features (14 [24.14\%] vs. 12 [9.76\%] in HCs; $p=0.01$ ).

HLA Class I and HFE in RAOU and BD
Compared with patients with mucocutaneous or joint involvement (SG2 and SG3), the isolated RAOU subgroup (SG1) had a lower frequency of HLA-A1 with a difference close to significance (12 [14.1\%] vs. 23 [25.8\%]; $p=0.07)$. The patients with mucocutaneous involvement had a higher frequency of HLA-B51 (14 [24.14\%]) vs. 12 $[10.7 \%] ; p=0.02)$. When comparing the 2 groups, the HLA-B51 frequency was significantly lower in the BDgroup $(26,15.29 \%)$ than in the $\mathrm{BD}+$ group $(17,27.42 \%$; $p=0.03)$. The HLA-B51 association with BD+ and BDpatients is illustrated in Figure 1 based on the clinical manifestations and in comparison with HCs.

\section{HFE Mutations}

The S65C mutation was not detected in the population studied. However, RFLP analysis revealed C282Y in 3 HCs and in none of the patients. The H63D distribution is given in Table 4. Compared with the HCs, the analysis did not reveal any significant difference in the distribution of the HFE mutation in the $\mathrm{BD}-$ and $\mathrm{BD}+$ groups. Compared with other patients with mucocutaneous or joint involvement, patients with isolated RAOU had a higher frequency of H63D mutation (29 [39.2\%] vs. 20 [24.4\%]; $p=0.04)$. This association strengthened and became more significant when comparisons were limited to patients of at least 5 years of follow-up (20 [50\%] vs. 7 [17.1\%]; $p=0.002)$.

\section{Discussion}

In this report, HLA-B51 was positively associated with $\mathrm{BD}$ patients when compared with HCs, which is consistent with the results of a previous study [13]. It has also been reported that HLA-B51 is considered as a risk factor in BD among Asian populations [14], Caucasians [15, 16], and Mediterranean people [17, 18].

Med Princ Pract 2017;26:427-432 DOI: $10.1159 / 000481782$ 
Table 3. HLA class I association with BD- patients according to clinical manifestations and in comparison with HCs

\begin{tabular}{lccccc}
\hline $\begin{array}{l}\text { HLA } \\
\text { antigen }\end{array}$ & BD- $(n=170)$ & SG1 $(n=81)$ & SG2 $(n=58)$ & SG3 $(n=25)$ & HCs $(n=123)$ \\
\hline A1 & $35(20.59)$ & $12(14.81)^{*}$ & $16(27.6)$ & $6(24)$ & $32(26.02)$ \\
A23 & $26(15.29)$ & $11(13.58)$ & $8(13.8)$ & $6(24)$ & $10(8.13)$ \\
A24 & $17(10)$ & $10(12.35)$ & $3(5.17)^{* *}$ & $3(12)$ & $20(16.26)$ \\
B8 & $16(9.41)$ & $5(6.2)$ & $8(13.8)$ & $1(4)$ & $16(13)$ \\
B27 & $6(3.53)$ & $3(3.7)$ & $3(5.17)$ & $4(16)$ & $3(2.44)$ \\
B35 & $21(12.35)$ & $10(12.35)$ & $6(10.34)$ & $1(4)$ & $17.07)$ \\
B51 & $26(15.29)$ & $10(12.35)$ & $14(24.14)^{* * *}$ & $19.76)$ \\
\hline
\end{tabular}

Data are presented as $n(\%)$. BD, Behçet disease; SG, subgroup; HCs, healthy controls. ${ }^{*} p=0.06$ when compared with HCs (OR 0.49 , $95 \%$ CI $0.24-1.02), p=0.07$ when compared with other subgroups of BD- patients; ${ }^{* *} p=0.04$ when compared with HCs (OR $0.28,95 \%$ CI $0.08-0.98) ;{ }^{* * *} p=0.01$ when compared with HCs (OR 2.94, 95\% CI 1.26-6.85), $p=0.02$ when compared with other subgroups of $\mathrm{BD}$ - patients.

Fig. 1. HLA-B51 association with $\mathrm{BD}+$ and $\mathrm{BD}$ - patients according to clinical manifestations and in comparison with HCs. BDJF, BD with joint features; RAOUJF, RAOU with joint features; RAOUMCF, RAOU with mucocutaneous features; BDMCF, BD with mucocutaneous features; HCs, healthy controls.

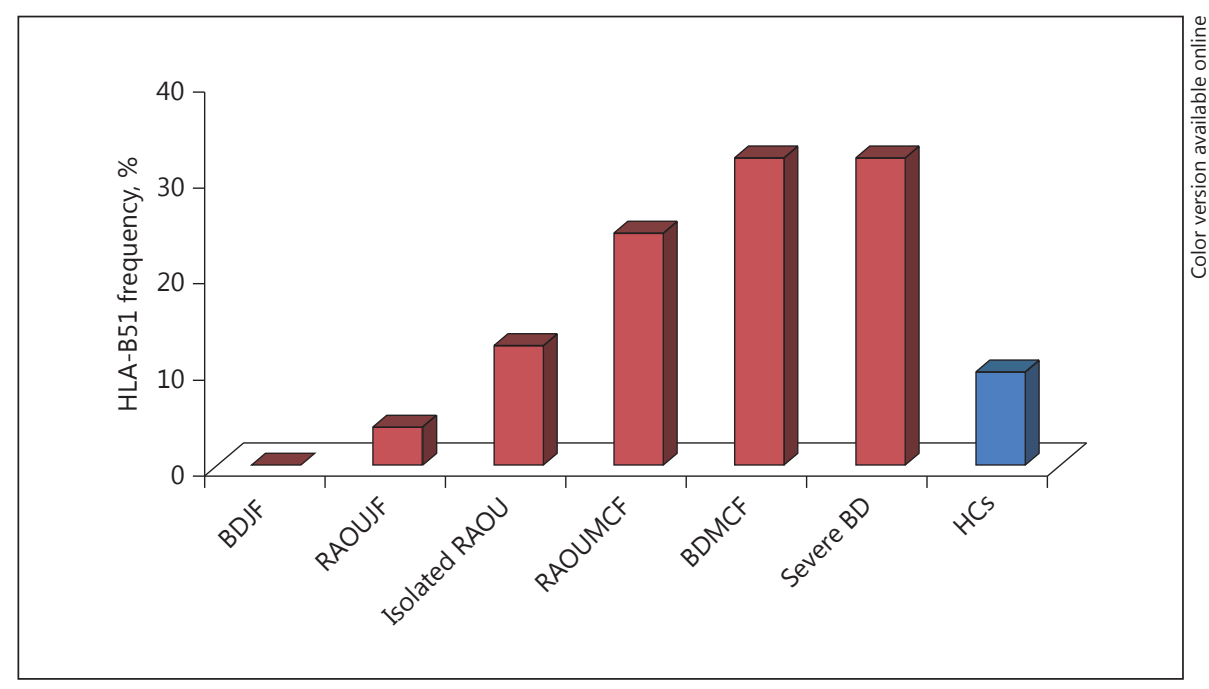

The finding that HLA-B35 was protective in these patients confirmed a report from Spain [19]. However, it contrasts with the findings of Shahneh et al. [20], who reported that HLA-B35 conferred susceptibility to BD in Iranians.

The finding of HLA class I disease phenotypic correlations revealed a significant positive association of HLAB51 with severe manifestations, including uveitis and vascular involvement. This confirmed the finding of Hamzaoui et al. [21] in which the HLA-B51 antigen was significantly associated with a positive pathergy test and retinal vasculitis.

HLA-B51 is the strongest susceptibility factor described so far affecting the disease risk. Nevertheless, a meta-analysis [22] provided evidence that HLA-B51 positivity had only a modest $\mathrm{BD}$ phenotype-modifying effect. Moreover, the strong association of HLA-B51 with BD could reflect linkage disequilibrium with another putative susceptibility gene. In fact, analyses of multicase families showed a substantial contribution of non-HLA loci on chromosome 6 at position D6S285, $13 \mathrm{Mb}$ telomeric to HLA-B [23].

RAOU is usually the initial feature of BD. It is a major criterion according to the International Study Group for Behçet's Disease criteria for the diagnosis of this disease [3]. It can be isolated for many years before developing other clinical features as part of BD. In this study, there was no association between the HLA class I polymor- 
Table 4. H63D mutation distribution in patients and HCs

\begin{tabular}{|c|c|c|c|c|c|c|c|c|}
\hline \multirow[t]{2}{*}{ H63D genotype } & \multicolumn{4}{|c|}{ BD- group $(n=156)$} & \multicolumn{3}{|c|}{$\mathrm{BD}+\operatorname{group}(n=52)$} & \multirow{2}{*}{$\begin{array}{l}\mathrm{HCs} \\
(n=123)\end{array}$} \\
\hline & $\begin{array}{l}\text { BD- } \\
(n=156)\end{array}$ & $\begin{array}{l}\text { SG1 } \\
(n=74)\end{array}$ & $\begin{array}{l}\text { SG2 } \\
(n=51)\end{array}$ & $\begin{array}{l}\text { SG3 } \\
(n=25)\end{array}$ & $\begin{array}{l}\mathrm{BD}+ \\
(n=52)\end{array}$ & $\begin{array}{l}\text { SGA } \\
(n=31)\end{array}$ & $\begin{array}{l}\text { SGB } \\
(n=21)\end{array}$ & \\
\hline $\mathrm{HD}$ or $\mathrm{DD}$ & $49(31.4)$ & $29(39.2)^{*}$ & $12(23.5)$ & $6(24)$ & $11(21.2)$ & $7(22.6)$ & $4(19.05)$ & $35(28.5)$ \\
\hline $\mathrm{HH}$ & $107(68.6)$ & $45(60.8)$ & $39(76.5)$ & $19(76)$ & $41(78.8)$ & $24(77.4)$ & $17(80.95)$ & $88(71.5)$ \\
\hline
\end{tabular}

Data are presented as $n(\%)$. BD, Behçet disease; SG, subgroup; HCs, healthy controls; HD, H63D heterozygote; DD, H63D homozygote; $\mathrm{HH}, \mathrm{H} 63 \mathrm{H}$ homozygote. ${ }^{*} p=0.04$ when compared with other subgroups of $\mathrm{BD}$ - patients.

phism and RAOU, but HLA-B51 association with mucocutaneous features could support the hypothesis that the presence of skin lesions in patients with RAOU could be a risk factor for the development of $\mathrm{BD}$ [2].

The results of other studies of HLA in RAOU patients remain inconsistent. In Turkish populations [24], there was no association between RAOU and HLA-B51. Pekiner et al. [25] found that the HLA-A24 frequency was significantly higher in the RAOU patient group than in healthy subjects. In Brazilians, RAOU was associated with HLA-A33, HLA-B35, and HLA-B81 [26]. In Caucasians, patients with RAOU showed a higher frequency of HLA-B12 [27], HLA-DR7, and HLA-DR5 [28], and lower incidence of HLA-B5 and HLA-DR4 [28] when compared with HCs. The discrepancies could be due to the ethnic background of the condition, but also might be a consequence of unequal patient qualification criteria. Nevertheless, a noteworthy similarity in all these studies, including ours, is the lack of association of HLA-B51 with RAOU.

We suggested that a susceptibility locus for RAOU could reside in the telomeric segment to HLA-B. The finding of a lack of association of $\mathrm{H} 63 \mathrm{D}$, the most common HFE mutation, with $\mathrm{BD}$ confirmed the previous findings of Gul et al. [23]. On the other hand, the present study revealed the association of $\mathrm{H} 63 \mathrm{D}$ with isolated RAOU.

Mutations in the HFE gene result in iron overload and disturb its intestinal absorption with consequent hereditary hemochromatosis [6]. The increased incidence of malignancy in patients with common HFE mutations remains controversial. They were implicated in breast [8], gastrointestinal [9], and liver [10] cancers. In fact, iron is a potential carcinogen [29]. It induces oxidative stress by catalyzing hydroxyl radical formation. Hussain et al. [30] found that $28 \%$ of hemochromatosis cases showed a higher expression of inducible nitric oxide synthase (NOS) in

HLA Class I and HFE in RAOU and BD the liver, which suggests NO as a source of increased oxidative stress. Some reports also suggest the role of endothelial NOS gene polymorphisms in the development of RAOU [5]. In fact, the development of a sustained oxidative and nitrosative stress, and the subsequent generation of lipid peroxidation, protein modification, and DNA damage can promote RAOU. Such results are in concordance with the high frequency of H63D mutation in our patients with isolated RAOU, which has not been previously reported.

\section{Conclusion}

BD was mainly associated with HLA-B51 in Southern Tunisia. This antigen was not associated with RAOU; however, it had an impact on clinical features associated with RAOU. Finally, this study is the first to confirm the association of $\mathrm{H} 63 \mathrm{D}$ with isolated RAS.

\section{Disclosure Statement}

The authors have no conflicts of interest to declare.

\begin{tabular}{|c|c|}
\hline References & $\begin{array}{l}1 \text { Field EA, Allan RB: Oral ulceration - aetio- } \\
\text { pathogenesis, clinical diagnosis and manage- } \\
\text { ment in the gastrointestinal clinic. Aliment } \\
\text { Pharmacol Ther 2003;18:949-962. } \\
2 \text { Nair JR, Moots RJ: Behcet's disease. Clin Med } \\
\text { 2017;17:71-77. } \\
3 \text { International Study Group for Behçet's Dis- } \\
\text { ease: Criteria for diagnosis of Behçet's disease. } \\
\text { Lancet 1990;335:1078-1080. } \\
4 \text { Wilhelmsen NS, Weber R, Monteiro F, et al: } \\
\text { Correlation between histocompatibility anti- } \\
\text { gens and recurrent aphthous stomatitis in the } \\
\text { Brazilian population. Braz J Otorhinolaryn- } \\
\text { gol 2009;75:426-431. }\end{array}$ \\
\hline
\end{tabular}

Med Princ Pract 2017;26:427-432 DOI: $10.1159 / 000481782$
431 
5 Slebioda Z, Szponar E, Kowalska A: Recurrent aphthous stomatitis: genetic aspects of etiology. Postepy Dermatol Alergol 2013;30:96102.

6 Feder JN, Gnirke A, Thomas W, et al: A novel MHC class I-like gene is mutated in patients with hereditary haemochromatosis. Nat Genet 1996;13:399-408.

7 Pacho A, Mancebo E, del Rey MJ, et al: HLA haplotypes associated with hemochromatosis mutations in the Spanish population. BMC Med Genet 2004;5:25.

8 Gunel-Ozcan A, Alyilmaz-Bekmez S, Guler EN, et al: HFE H63D mutation frequency shows an increase in Turkish women with breast cancer. BMC Cancer 2006;6:37.

9 Agudo A, Bonet C, Sala N, et al: Hemochromatosis (HFE) gene mutations and risk of gastric cancer in the European Prospective Investigation into Cancer and Nutrition (EPIC) study. Carcinogenesis 2013;34:1244-1250.

10 Ropero P, Briceño O, López-Alonso G, et al: The H63D mutation in the HFE gene is related to the risk of hepatocellular carcinoma. Rev Esp Enferm Dig 2007;99:376-381.

11 De Souza GF, Ribeiro HL Jr, De Sousa JC, et al: HFE gene mutation and oxidative damage biomarkers in patients with myelodysplastic syndromes and its relation to transfusional iron overload: an observational cross-sectional study. BMJ Open 2015;5:e006048.

12 Barry E, Derhammer T, Elsea SH: Prevalence of three hereditary hemochromatosis mutant alleles in the Michigan Caucasian population. Community Genet 2005;8:173-179.

13 Kamoun A, Mahfoudh N, Frigui M, et al: Association of HLA class I antigens with Behçet disease in South Tunisia. Pathol Biol 2012; 60:e59-e64.
14 Demirseren DD, Ceylan GG, Akoglu G, et al: HLA-B51 subtypes in Turkish patients with Behçet's disease and their correlation with clinical manifestations. Genet Mol Res 2014; 13:4788-4796.

15 Montes-Cano MA, Conde-Jaldón M, GarcíaLozano JR, et al: HLA and non-HLA genes in Behçet's disease: a multicentric study in the Spanish population. Arthritis Res Ther 2013; 15:R145.

16 Bettencourt A, Pereira C, Carvalho L, et al: New insights of HLA class I association to Behçet's disease in Portuguese patients. Tissue Antigens 2008;72:379-382.

17 B'chir Hamzaoui S, Harmel A, Bouslama K, et al: Behçet's disease in Tunisia: clinical study of 519 cases. Rev Med Interne 2006;27:742750 .

18 Choukri F, Chakib A, Himmich H, et al: HLA$\mathrm{B}^{*} 51$ and $\mathrm{B}^{*} 15$ alleles confer predisposition to Behçet's disease in Moroccan patients. Hum Immunol 2001;62:180-185.

19 Montes-Cano MA, Conde-Jaldón M, GarcíaLozano JR, et al: HLA and non-HLA genes in Behçet's disease: a multicentric study in the Spanish population. Arthritis Res Ther 2013; 15:R145.

20 Shahneh FZ, Hamzavi F, Bayazi B, et al: New insights into HLA class I association to Behçet's syndrome in Iranian Azari patients. Auto Immun Highlights 2013;4:101-102.

21 Hamzaoui A, Houman MH, Massouadia M, et al: Contribution of Hla-B51 in the susceptibility and specific clinical features of Behcet's disease in Tunisian patients. Eur J Intern Med 2012;23:347-349.

22 Maldini C, Lavalley MP, Cheminant M, et al: Relationships of HLA-B51 or B5 genotype with Behcet's disease clinical characteristics: systematic review and meta-analyses of observational studies. Rheumatology 2012;51: 887-900.
23 Gul A, Hajeer AH, Worthington J, et al: Linkage mapping of a novel susceptibility gene for Behçet's disease to chromosome 6p22-23. Arthritis Rheum 2001;44:2693-2696.

24 Ozdemir M, Acar H, Deniz F, et al: HLA-B*51 in patients with recurrent aphthous stomatitis. Acta Derm Venereol 2009;89:202-203.

25 Pekiner FN, Aytugar E, Demirel GY, et al: HLA-A, B (class I) and HLA-DR, DQ (class II) antigens in Turkish patients with recurrent aphthous ulceration and Behçet's disease. Med Princ Pract 2013;22:464-468.

26 Wilhelmsen NS, Weber R, Monteiro F, Kalil $\mathrm{J}$, et al: Correlation between histocompatibility antigens and recurrent aphthous stomatitis in the Brazilian population. Braz J Otorhinolaryngol 2009;75:426-431.

27 Malmström M, Salo OP, Fyhrquist F: Immunogenetic markers and immune response in patients with recurrent oral ulceration. Int J Oral Surg 1983;12:23-30.

28 Gallina G, Cumbo V, Messina P, et al: HLA-A, $\mathrm{B}, \mathrm{C}, \mathrm{DR}, \mathrm{MT}$, and $\mathrm{MB}$ antigens in recurrent aphthous stomatitis. Oral Surg Oral Med Oral Pathol 1985;59:364-370.

29 Fargion S, Valenti L, Fracanzani AL: Hemochromatosis gene (HFE) mutations and cancer risk: expanding the clinical manifestations of hereditary iron overload. Hepatology 2010; 51:1119-1121.

30 Hussain SP, Raja K, Amstad PA, et al: Increased p53 mutation load in nontumorous human liver of Wilson disease and hemochromatosis: oxyradical overload diseases. Proc Natl Acad Sci USA 2000;97:1277012775. 